\title{
Avaliação da eficiência judiciária em casos de violência sexual contra mulheres
}

\author{
Judicial efficiency evaluation in sexual violence cases against women
}

Evaluación de la eficiencia judicial en casos de violencia sexual contra la mujer

Agda Barbosa Mesquita ${ }^{1 *}$, Idna Karime de Sousa Silva ${ }^{1}$, Francisco de Jesus Lima², Auricélia do Nascimento Melo ${ }^{1}$, Maria Castelo Branco Rocha de Deus ${ }^{3}$, Luciana Tolstenko Nogueira ${ }^{1}$, Lucielma Salmito Soares Pinto'.

\section{RESUMO}

Objetivo: Avaliar a eficiência judiciária em casos de violência sexual contra mulheres. Métodos: Tratou-se de estudo do tipo observacional, quantitativo e retrospectivo realizado a partir da análise documental de casos de violência sexual contra mulheres atendidas inicialmente em Serviço de Atenção à Mulher Vítima de Violência Sexual (SAMVVIS) e cujo processo judiciário correspondente tenha sido localizado na base de dados do Ministério Público. Resultados: $68 \%$ das vítimas eram menores de 18 anos, em $52 \%$ dos casos a violência ocorreu na residência da vítima e o agressor era familiar ou conhecido da vítima (62\%). A média de audiências realizadas por processo foi 0,41 , sendo que em 26 processos (52\%) ainda não havia sido realizada nenhuma audiência. Apenas $13(26 \%)$ casos constam como concluídos, e em apenas $5(38,5 \%)$ destes casos, o réu foi condenado, sendo adotadas penas de medidas preventivas e privativas de liberdade. Observou-se que os agressores sem vínculo familiar com a vítima foram privados de liberdade mais frequentemente do que os com vínculo familiar. Conclusão: Os resultados apontam para a ineficiência do judiciário, considerando a realização de poucas audiências e de poucas baixas nos processos.

Palavras-chave: Delitos sexuais, Poder Judiciário, Eficiência, Mulheres.

\begin{abstract}
Objective: To evaluate judicial efficiency in cases of sexual violence against women. Methods: This was an observational, quantitative and retrospective study carried out based on documentary analysis of sexual violence cases against women, who were initially treated at the Service of Attention to Women Victims of Sexual Violence (SAMVVIS) and whose corresponding judicial process has been located at Public Prosecutor's database. Results: $68 \%$ of the victims were under 18 years old, in $52 \%$ of the cases the violence occurred at the victim's residence and the aggressor was family or known to the victim (62\%). The average number of hearings per process was 0.41 with 26 cases $(52 \%)$ that did not had a hearing yet. Only $13(26 \%)$ cases are concluded, and in only $5(38.5 \%)$ of these cases, the defendant was convicted, with penalties of preventive and custodial measures adopted. Aggressors without a family link with the victim were more often deprived of their freedom. Conclusion: The results point to the inefficiency of the judiciary, considering the holding of few hearings and few casualties in the proceedings.
\end{abstract}

Keywords: Sex offenses, Judiciary, Efficiency, Women.

\footnotetext{
${ }^{1}$ Universidade Estadual do Piauí (UESPI), Teresina - PI. *E-mail: agdamesquita@aluno.uespi.br

2 Ministério Público Estadual do Piauí, Teresina - PI.

${ }^{3}$ Secretaria de Saúde do Estado do Piauí (SESAPI), Teresina - PI.
}

Pesquisa sob incentivo do edital de Iniciação Científica do Conselho Nacional de Desenvolvimento Científico e Tecnológico (CNPq). 


\section{RESUMEN}

Objetivo: Evaluar la eficiencia judicial en casos de violencia sexual contra la mujer. Métodos: Se trata de un estudio observacional, cuantitativo y retrospectivo realizado a partir del análisis documental de casos de violencia sexual contra mujeres atendidos inicialmente en el Servicio de Atención a Mujeres Víctimas de Violencia Sexual (SAMVVIS) y cuyo correspondiente proceso judicial ha sido localizado, en la base de datos del Ministerio Público. Resultados: El 68\% de las víctimas eran menores de 18 años, en el $52 \%$ de los casos la violencia ocurrió en el domicilio de la víctima y el agresor era familiar o conocido de la víctima (62\%). El número medio de audiencias por proceso fue de 0,41 , y 26 casos (52\%) aún no han tenido audiencia. Solo $13(26 \%)$ casos están concluidos, y en solo 5 (38,5\%) de estos casos el imputado fue condenado, con sanción de medidas preventivas y privativas de libertad. Se observó que los agresores $\sin$ vínculo familiar con la víctima eran privados de su libertad con mayor frecuencia que los que tenían vínculo familiar. Conclusión: Los resultados apuntan a la ineficiencia del poder judicial, considerando la celebración de pocas audiencias y pocas bajas en los procesos

Palabras clave: Delitos sexuales, Poder Judicial, Eficiencia, Mujer.

\section{INTRODUÇÃO}

A violência sexual contra as mulheres é uma grave violação dos direitos humanos. Apesar das estatísticas serem frágeis e as exatas incidência e prevalência serem desconhecidas, estima-se que afete cerca de 12 milhões de pessoas a cada ano no mundo (BRASIL, 2012).

Essa violência é compreendida como qualquer ato sexual ou tentativa, comentários ou investidas sexuais indesejadas, de alguma forma, voltados contra a sexualidade da mulher, usando a coação, praticada por qualquer pessoa, independentemente de suas relações, em qualquer cenário, inclusive no domicílio e no trabalho, mas não limitada a eles (DELZIOVO CR, et al., 2018). É considerado acima de tudo, um problema de saúde pública, pois entre as consequências que esse tipo de violência acarreta em suas vítimas, além de sérios enfrentamentos psicológicos, há a possibilidade de gravidez e de contaminação por Infecções Sexualmente Transmissíveis (ISTs) (CAMPOS MAMR e SCHOR N, 2008).

Séries temporais têm relatado significativa tendência de crescimento para a taxa de estupros e estupros intradomiciliares para 100 mil habitantes. As notificações de violência sexual triplicaram de 2009 a 2013 no Brasil, e quase quadruplicaram no Nordeste, o que pode ser atribuído não só ao aumento real do número de casos, maior conscientização das vítimas e/ou profissionais de saúde que fazem o acolhimento, como também por melhor estruturação e quantidade de unidades notificantes (GASPAR RS e PEREIRA MUL, 2018).

O perfil das vítimas é diverso e mulheres são violentadas independente de situação civil, religiosa ou ocupacional. É frequente, porém, se observar que as mulheres correm perigo em sua realidade cotidiana, haja vista que mais da metade dos agressores têm contato direto com as vítimas (OLIVEIRA GLOJ, et al., 2016).

Em resposta a pressões de movimentos feministas e da própria sociedade, os governos têm implementado políticas públicas e ações de prevenção de violência contra a mulher. Uma das estratégias principais tem sido criar e aprimorar normas, bem como expandir serviços com o objetivo de assistir integralmente às vítimas (KISS L, et al., 2012). No Brasil, a assistência em saúde às vítimas é prestada pelo Sistema Único de Saúde (SUS), com destaque para os Serviços de Atenção às Mulheres Vítimas de Violência Sexual (SAMVVIS), que visam a redução do risco de doença e o acesso universal e igualitário às ações e serviços para promoção, proteção e recuperação de saúde e têm se mostrado eficazes neste sentido (PINTO LSS, et al., 2017).

Quanto à assistência jurídica, o acionamento ou não da Justiça é uma escolha da vítima, a não ser em casos que envolvem crianças e adolescentes, quando o conselho tutelar é acionado pela equipe de saúde (SOUSA EA, 2018). A mulher pode acionar diretamente a polícia, dando início a um inquérito policial. Após 
investigação da matéria, o caso é levado ao conhecimento do sistema jurídico, com o acusado podendo ou não ser indiciado pela denúncia (CRUZ MM, 2019). Nos crimes de violência contra a mulher, a impunidade é um problema crítico, visto que frequentemente essa violência se manifesta na esfera privada, no âmbito das famílias e do próprio lar, nas relações entre parceiros íntimos, familiares, amigos e conhecidos, obrigando o convívio entre agressor e vítima (DELZIOVO CR, et al., 2018).

No plano do Poder Judiciário brasileiro, a eficiência está diretamente ligada à entrega da tutela jurisdicional, da satisfação do direito pleiteado, com menor custo orçamentário e em tempo razoável. A constatação do descompasso entre o tempo de duração de um processo para certificação do direito e a efetiva satisfação da tutela requerida pelo cidadão sempre foi motivo de grande preocupação (REYMÃO AEN, et al., 2019). Parcela significativa da população desacredita no sistema judicial brasileiro, existindo um temor de que os casos de violência sexual não sejam investigados com o rigor que merecem, culminando na não punição dos responsáveis (BEDONE AJ e FAÚNDES A, 2007).

Considerando que pouco se sabe sobre a assistência judiciária às mulheres vítimas de violência sexual, o objetivo do presente estudo foi avaliar a eficiência judiciária em casos de violência sexual contra a mulher, por meio da análise do tempo de tramitação e do status dos processos judiciais tendo decorrido pelo menos 5 anos do atendimento inicial de violência sexual dessas vítimas.

\section{MÉTODOS}

O presente estudo foi do tipo observacional, quantitativo e retrospectivo realizado a partir da análise documental de casos de violência sexual contra mulheres, atendidas inicialmente no Serviço de Atenção à Mulher Vítima de Violência Sexual (SAMVVIS) de Teresina-PI e cujo processo judiciário correspondente tenha sido localizado na plataforma THEMIS Web, base de dados eletrônica usada pelo Ministério Público do Estado do Piauí. O protocolo do estudo foi conduzido em total acordo com a Resolução no-466/2013 do Conselho Nacional de Saúde e Declaração de Helsinki e foi aprovado pelo Comitê de Ética local (CAAE: 67436717.3.0000.5209).

Os critérios de inclusão foram: atendimento inicial pelo SAMVVIS há pelo menos 5 anos (tempo estimado para instauração de inquérito e tramitação processual), prontuário completamente preenchido e processo judiciário correspondente localizado na plataforma THEMIS. Foram excluídos os casos com prontuários incompletos e aqueles cujos processos judiciários não foram localizados. Deste modo, foram selecionados para esse estudo dados referentes a 50 casos de violência sexual contra mulheres, de um total de 290 casos atendidos no SAMVVIS de Teresina, PI, no período de janeiro a outubro de 2011.

A coleta dos dados foi realizada por meio de prontuários e dos processos judiciais correspondentes às agressões. Iniciou-se pela consulta aos prontuários, para coleta de informações das vítimas e dos agressores, como idade, escolaridade, ocupação, renda, uso de substâncias tóxicas e relação de parentesco, além de dados referentes à agressão. Posteriormente, procedeu-se a coleta dos dados referentes às ações judiciais das referidas vítimas no Sistema da Justiça, quais sejam: data de início da ação, número de audiências, privação de liberdade do acusado em algum momento do processo e situação processual.

Os dados obtidos nos sistemas de saúde e de justiça foram tabulados no programa Microsoft Excel 2016 para análise e apresentação estatística descritiva. Testes de associação do x2 (qui-quadrado) com nível de significância de $5 \%(\alpha=0,05)$ foram realizados.

\section{RESULTADOS}

Os prontuários de 290 mulheres vítimas de violência sexual inicialmente atendidas no SAMVVIS foram acessados, destes, apenas $50(17,24 \%)$ tiveram seu processo judiciário localizado, sendo, portanto, incluídos no presente estudo. 15 (30\%) desses casos estavam sob segredo de justiça, tendo sido coletadas apenas as informações disponíveis. 
As mulheres vítimas de violência cujos processos foram analisados eram em sua maioria menores de 18 anos (68\%). Houve predomínio da faixa etária dos 11 aos 15 anos (42\%). A agressão foi praticada durante a noite em $44 \%$ dos casos, sem uso de arma para intimidação (60\%) e na própria residência da vítima em $52 \%$ dos casos, sendo citadas também a residência do agressor, via pública e outros. Na maioria dos casos o agressor era o companheiro ou ex-companheiro (24\%), seguido por vizinho $(20 \%)$ e pai ou padrasto (18\%) (Tabela 1).

Tabela 1 - Perfil dos casos de violência sexual contra mulheres, $n=50$. Teresina-PI, 2021.

\begin{tabular}{|c|c|c|}
\hline Variável & $\mathbf{N}$ & $\%$ \\
\hline \multicolumn{3}{|l|}{ Faixa etária das vítimas } \\
\hline $0-5$ anos & 6 & 12 \\
\hline $6-10$ anos & 5 & 10 \\
\hline $11-15$ anos & 21 & 42 \\
\hline $16-20$ anos & 5 & 10 \\
\hline 21-25 anos & 2 & 4 \\
\hline $26-30$ anos & 7 & 14 \\
\hline 31-35 anos & 1 & 2 \\
\hline $36-40$ anos & 0 & 0 \\
\hline 41-45 anos & 2 & 4 \\
\hline Não informado & 1 & 2 \\
\hline \multicolumn{3}{|l|}{ Turno da agressão } \\
\hline Manhã & 9 & 18 \\
\hline Tarde & 6 & 12 \\
\hline Noite & 22 & 44 \\
\hline Não informado & 13 & 26 \\
\hline \multicolumn{3}{|l|}{ Intimidação } \\
\hline Sem uso de arma & 30 & 60 \\
\hline Arma de fogo & 2 & 4 \\
\hline Arma branca & 1 & 2 \\
\hline Não informado & 17 & 34 \\
\hline \multicolumn{3}{|l|}{ Local da agressão } \\
\hline Residência da vítima & 26 & 52 \\
\hline Residência do agressor & 6 & 12 \\
\hline Via pública & 10 & 20 \\
\hline Outros & 4 & 8 \\
\hline Não informado & 4 & 8 \\
\hline Total & 100 & - \\
\hline
\end{tabular}

Fonte: Mesquita AB, et al., 2021.

O intervalo entre o atendimento inicial no estabelecimento de saúde e o acionamento da Justiça em período superior a 1 mês e inferior a 1 ano foi observado em $56 \%$ dos casos, ao passo que apenas $20 \%$ das mulheres denunciaram o agressor em até 1 mês. Analisando-se o andamento das ações, dentre os 50 
processos estudados, em 26 (52\%) ainda não havia sido realizada nenhuma audiência e em 16 (32\%) a informação não estava disponível. Apenas $8(16 \%)$ casos tiveram audiências realizadas, deste modo, a média de audiências realizadas foi de apenas 0,41 audiência por processo (Tabela 2).

Tabela 2 - Análise dos processos judiciários de mulheres vítimas de violência sexual, $n=50$. Teresina-PI, 2021.

\begin{tabular}{|c|c|c|}
\hline Variável & $\mathbf{N}$ & $\%$ \\
\hline \multicolumn{3}{|c|}{ Intervalo entre o atendimento inicial no SAMVVIS e o acionamento do sistema de Justiça } \\
\hline 1 dia & 4 & 8 \\
\hline 2 dias a 1 mês & 6 & 12 \\
\hline 1 mês a 1 ano & 23 & 46 \\
\hline Superior a 1 ano & 5 & 10 \\
\hline Não informado & 12 & 24 \\
\hline \multicolumn{3}{|c|}{ Andamento da ação (número de audiências realizadas) } \\
\hline Nenhuma audiência & 26 & 52 \\
\hline Pelo menos 1 audiência & 8 & 16 \\
\hline Não informado & 16 & 32 \\
\hline \multicolumn{3}{|c|}{ Adoção de medidas privativas de liberdade ao longo da ação } \\
\hline Nenhuma & 32 & 64 \\
\hline Flagrante & 7 & 14 \\
\hline Preventiva & 2 & 4 \\
\hline Após sentença & 3 & 6 \\
\hline Não informada & 6 & 12 \\
\hline \multicolumn{3}{|l|}{ Status dos casos } \\
\hline Em andamento & 37 & 74 \\
\hline Concluídos & 13 & 26 \\
\hline \multicolumn{3}{|l|}{ Desfecho dos processos que foram concluídos } \\
\hline Condenação do réu & 5 & 38,4 \\
\hline Absolvição do réu ou extinção do processo & 8 & 61,5 \\
\hline \multicolumn{3}{|l|}{ Pena } \\
\hline Medida preventida & 2 & 40 \\
\hline Reclusão de 2 anos & 2 & 40 \\
\hline Reclusão de 60 anos & 1 & 20 \\
\hline Total & 50 & 100 \\
\hline
\end{tabular}

Fonte: Mesquita AB et al., 2021.

Com relação ao status das ações, $37(74 \%)$ casos constam como em andamento, ao passo que 13 (26\%) foram concluídos. Dentre os concluídos, em 8 (61,5\%), os acusados foram absolvidos ou houve extinção do processo; e em $5(38,5 \%)$ o réu foi condenado, tendo como penas: medidas preventivas em 2 casos, reclusão de dois anos em 2 casos e reclusão de 60 anos em 1 caso. Informações sobre medidas privativas de liberdade estavam disponíveis em 44 (88\%) dos casos. No total, $12(25 \%)$ denunciados foram efetivamente presos em algum momento do curso jurídico, dentre os quais $7(58,3 \%)$ foram em flagrante, 3 
(25\%) após a sentença e $2(16,7 \%)$ preventivamente. (Tabela 2). Contra um dos acusados, que era pai da vítima, foi expedido mandado de segurança, mas o mesmo encontrava-se foragido. O tempo médio de reclusão foi 20 meses e 12 dias, considerando apenas os casos em que houve adoção dessa medida em qualquer momento do processo.

Dentre os agressores que foram privados de liberdade, 9 não possuíam vínculo familiar (vizinhos e desconhecidos), ao passo que 3 ocupavam a posição de pai, padrasto ou companheiro. Os agressores vizinhos ou desconhecidos foram privados de liberdade com mais frequência do que os agressores que possuíam alguma relação de vínculo familiar com as vítimas, o que foi estatisticamente significante $(p=0,0491)$ (Tabela 3).

Tabela 3 - Correlação entre relação de parentesco entre vítima e agressor e a condição de privação de liberdade. Teresina-PI, 2021.

\begin{tabular}{lccc}
\hline Variável & $\mathbf{N}$ & $\%$ & \multirow{2}{*}{$\mathbf{p}^{\star}$} \\
\cline { 1 - 3 } Pai, padrasto, companheiro ou ex-companheiro & & & \\
\cline { 1 - 3 } Foi privado de liberdade & 3 & 27,27 & \\
Não foi privado de liberdade & 18 & 62,07 & \\
Total & 21 & 52,50 & \\
\cline { 1 - 3 } Vizinho ou desconhecido & & & \\
\cline { 1 - 3 } Foi privado de liberdade & 8 & 72,73 & \\
Não foi privado de liberdade & 11 & 37,93 & \\
Total & 19 & 47,50 & \\
\hline
\end{tabular}

Legenda: *Teste de Qui-quadrado

Fonte: Mesquita $\mathrm{AB}$ et al., 2021.

\section{DISCUSSÃO}

Em meio aos crimes contra a liberdade sexual, o estupro é tipificado no art. 213 do Código Penal Brasileiro, consistindo no constrangimento de alguém, mediante violência ou grave ameaça, a ter conjunção carnal ou a praticar ou permitir que com ele se pratique outro ato libidinoso. Atualmente, a pena no Brasil é de 6 a 10 anos de reclusão; aumentando para 8 a 12 anos se há lesão corporal da vítima ou se a vítima possui entre 14 a 18 anos de idade; e para 12 a 30 anos, se a conduta resulta em morte. Ainda, se a vítima for considerada vulnerável, menor de 14 anos, alienados mentais ou pessoas que não puderem oferecer resistência, a pena é aumentada (BRASIL, 2009).

Pena é a sanção penal de caráter aflitivo imposta pelo Estado, para aplicação de uma sentença, a um indivíduo que comete uma infração penal, como forma não apenas de puni-lo, mas também de reprimir e prevenir uma futura empreitada por parte de outros indivíduos. A pena atua na prevenção de crimes ao objetivar a segregação social e posterior ressocialização do criminoso como meios de impedi-lo de voltar a delinquir e pela intimidação dirigida ao ambiente social (CAPEZ F, 2019). Foi neste contexto, que o presente estudo se propôs avaliar a eficiência judiciária por meio da análise do tempo de tramitação e status dos processos judiciais dessas vítimas.

O presente estudo avaliou 50 casos de violência sexual contra mulheres a partir de seus prontuários de atendimento inicial no serviço de saúde e posteriormente dos seus processos judiciais. Houve intencionalidade no desenho metodológico, haja visto que ao invés de serem investigados casos diretamente no banco de dados da justiça, escolheu-se iniciar a coleta no sistema de saúde a fim de identificar a parcela desses casos que efetivamente chega ao sistema judiciário. Nesse sentido, é importante destacar que da população de 290 vítimas atendidas no serviço de saúde, apenas 50 (17,24\%) 
processos judiciais foram identificados. Embora não se possa assegurar a infalibilidade das ferramentas de busca, é provável que muitos desses casos não tenham sido efetivamente denunciados, com poucos inquéritos de fato instaurados e processos iniciados.

O indicador de acesso à Justiça do Estado do Piauí é bastante inferior à média nacional, contando com 5.181 processos por 100.000 habitantes em 2018, na Justiça Estadual, enquanto a média brasileira foi de 8.325 por 100.000 habitantes no mesmo período (BRASIL, 2019). A este cenário, acrescentam-se as dificuldades de acesso particulares aos casos de violência sexual, como a insuficiência de instituições para atendimento especializado, profissionais despreparados, morosidade, falta de comunicação e de articulação interinstitucionais (DESLANDES SF e CAMPOS DS, 2015).

Estudo realizado no Rio de Janeiro exibiu que diante de 41 casos de violência sexual, poucos inquéritos foram instaurados e apenas um foi convertido em processo, caso em que o réu foi considerado inocente, provavelmente por falta de provas. Nesta amostra, alguns inquéritos foram arquivados e outros continuavam em andamento, mas possivelmente seriam arquivados em razão do tempo. Apontou-se a falta de provas como um fator importante, resultante da ineficiência da própria polícia, pela não realização dos exames necessários para a caracterização do crime e por nem sempre se preocupar com a existência de testemunhas. Também a inércia dos representantes legais das crianças e adolescentes concorre para a não instauração dos inquéritos. Estes, quando não são os próprios agressores, podem não ser atuantes, esclarecidos o suficiente ou dispor dos recursos necessários (GOMES R, 1998).

Dentre os casos de processos judiciais analisados no presente estudo, $68 \%$ das vítimas eram menores de 18 anos. Os dados apresentados são concordes com o descrito na literatura, que mostra que a violência sexual afeta comumente crianças e adolescentes (CAMPOS MAMR e SCHOR N, 2008; TRIGUEIRO TH, et al., 2015; PLATT VB, et al., 2018). Quanto aos autores dos abusos, pai, padrasto e companheiro (ex ou atual) são a maioria dos agressores, com a violência tendo ocorrido no domicílio da vítima na maioria das vezes, e sem uso de armas para intimidação. O turno mais frequentemente reportado foi a noite.

Evidencia-se que a violência sexual frequentemente se manifesta no seio familiar, nas relações íntimas entre parentes e amigos, obrigando o convívio entre agressor e vítima após o abuso (DELZIOVO CR, et al., 2018; CAMPOS MAMR e SCHOR N, 2008; PLATT VB, et al., 2018). Esse dado reforça a urgência por celeridade, pois além das sequelas físicas e psicológicas que podem ser determinantes por toda a vida da mulher, a vítima perde ainda a sensação de segurança em seu próprio lar (FONTAN RD e SILVA VO, 2019).

A maioria das vítimas demorou mais de um mês para dar início ao processo jurídico, o que pode sugerir dificuldades no acesso ou desconhecimento do percurso até se chegar ao judiciário. É também relatado na literatura que mulheres percebem com desconfiança o governo e as leis de proteção a mulher, além de acreditarem na ineficácia do setor judiciário, fatores que podem desencorajar a abertura de inquéritos e processos (EVANS DP, et al, 2020). Adicionalmente, mais da metade dos casos não apresentavam nenhuma audiência, resultando em uma média geral de apenas 0,41 audiências realizadas por processo. Com relação à conclusão dos casos, apenas $13(26 \%)$ constavam como concluídos, mesmo com tempo superior a 5 anos de tramitação.

Calcula-se que em média para a solução de uma ação judiciária, é necessário um tempo mínimo de quatro anos (SILVA LMP, et al., 2012). Dado semelhante foi apontado pelo Conselho Nacional de Justiça (CNJ), em que o tempo médio de baixa dos processos referentes às execuções judiciais criminais privativas de liberdade na Justiça Estadual foi 4 anos e 2 meses (BRASIL, 2019). Na última série histórica de movimentação processual brasileira disponibilizada pelo CNJ, referente aos dados de 2009 a 2018, observou-se que a finalização de processos é um problema global, visto que o número de casos pendentes na Justiça Criminal, equivale a 2,9 vezes a demanda e, ainda que o número de casos baixados tenha levemente superado os novos casos, o acervo cresceu (BRASIL, 2019).

Um achado incidental do estudo foi à observação frequente de declaração de incompetência por parte dos juízes, que por anos alternam a vara responsável pelo processo sem resolutividade. Tal achado pode 
refletir a falta de direcionamento adequado desses crimes dentro do próprio organograma judiciário. A Lei de Organização Judiciária do Estado do Piauí foi publicada em 1979, tendo sido submetida apenas a alterações pontuais (PIAUÍ, 2015).

A defasagem legislativa pode ter influência nos julgamentos de crimes desta natureza, favorecendo a impunidade dos agressores e corroborando com a inconsistência da assistência pós-violência prestada à vítima. Além deste ponto, aspectos quantitativos e qualitativos de recursos humanos, a falta de qualificação para atuarem em questões da infância e adolescência, além de, em alguns casos, precariedade de estrutura física tem culminado na deficiência de resposta do judiciário à sociedade nos casos de crimes de violência sexual contra mulheres (SILVA LMP, et al., 2012).

Dentre os processos finalizados, na maioria dos casos, os acusados foram absolvidos ou houve extinção do processo e em apenas 5 casos o réu foi condenado, tendo como penas: medidas preventivas, como a proibição de aproximação após uma distância mínima do agressor para com a vítima, em 2 casos, reclusão de dois anos, em 2 casos, e reclusão de 60 anos, em 1 caso. Dados semelhantes foram descritos em estudo no Pernambuco, referente a casos de violência sexual contra crianças e adolescentes, em que em 1 ano, de 161 processos com desfecho, mais da metade teve extinção de punibilidade ou do processo; e apenas em cerca de $1 / 3$ dos casos houve análise de mérito. Deste modo, os desfechos predominantes dos processos são aqueles que refletem a falta de efetividade da justiça (SILVA LMP, et al., 2012).

As medidas protetivas têm se mostrado ineficazes para a prevenção da recorrência, visto que na prática não diminuem o acesso do agressor à vítima, especialmente no caso de crianças agredidas pelas figuras paternas - pais, padrastos e avôs (AZAMBUJA MRF, 2006). Elas são, sobretudo, uma ação emergencial que por vezes funcionam em interromper a violência, mas que também produzem alto custo emocional pelas novas situações, dores e constrangimentos (SANTOS VA, 2010).

De acordo com as informações disponíveis sobre medidas privativas de liberdade, $24 \%$ dos acusados foram presos em algum momento do processo. Observou-se que aqueles que não possuíam vínculo familiar com as vítimas foram mais presos em flagrante, tiveram prisão preventiva ou foram condenados à reclusão do que os que os que possuíam vínculo, como pai/padrasto ou companheiro. Tal achado pode evidenciar que a tradicional "barreira privada" entre as esferas doméstica e pública não somente tem inibido a evolução de políticas e instrumentos legais para prevenir a violência intrafamiliar, como tem dificultado a punição dos agressores, expondo indefinidamente as vítimas aos seus algozes (PLATT VB, et al., 2018).

Entretanto, não há concordância a respeito na literatura, existindo séries de casos nas quais os agressores intradomiciliares tiveram as denúncias mais frequentemente convertidas em inquérito e em processos e foram mais frequentemente privados de liberdade que os agressores desconhecidos; possivelmente porque estes últimos são de difícil identificação quando não há flagrante (VARGAS JD, 1999).

Como pontos fortes, o presente estudo divulga dados em uma área carente de informações, que podem ser utilizados como subsídios para análise e formulação de políticas públicas para assistência judiciária às mulheres vítimas de violência. Entretanto, há limitações inerentes à metodologia de uso de dados secundários e desenho retrospectivo, sujeito a dados incompletos insanáveis, que, todavia, não invalidam os resultados obtidos (GASPAR RS e PEREIRA MUL, 2018).

\section{CONCLUSÃO}

Os dados do presente estudo exibiram que as mulheres vítimas de violência sexual têm pouco acesso à justiça e que, quando conseguem acioná-la, o curso processual é moroso, com tempo de tramitação médio maior que cinco anos e baixa taxa de conclusão de processos. Deste modo, pode-se concluir pela ineficiência do Judiciário no julgamento dos casos de violência sexual. Destaca-se a necessidade da realização de mais estudos para melhor identificação e compreensão dos pontos críticos de acesso a Justiça, a fim de que se ofereça um serviço capaz de efetivamente proteger vítimas e punir culpados. 


\section{REFERÊNCIAS}

1. AZAMBUJA MRF. Violência sexual intrafamiliar: é possível proteger a criança?. Textos \& Contextos (Porto Alegre), Porto Alegre, 2006; 5(1): 1-19.

2. BEDONE AJ, FAÚNDES A. Atendimento integral às mulheres vítimas de violência sexual: centro de assistência integral à saúde da mulher, universidade estadual de campinas. Cadernos de Saúde Pública, 2007; 23(2): 465-469.

3. BRASIL. Lei no 12015, de 7 de agosto de 2009. Altera o Título VI da Parte Especial do Decreto-Lei no 2.848 , de 7 de dezembro de 1940 - Código Penal, e o art. 10 da Lei no 8.072, de 25 de julho de 1990, que dispõe sobre os crimes hediondos, nos termos do inciso XLIII do art. 50 da Constituição Federal e revoga a Lei no 2.252, de 10 de julho de 1954, que trata de corrupção de menores. Lei. Brasília.

4. BRASIL. Ministério da Saúde. Secretaria de Atenção à Saúde. Departamento de Ações Programáticas Estratégicas. Prevenção e tratamento dos agravos resultantes da violência sexual contra mulheres e adolescentes. Brasília: Editora do Ministério da Saúde, 2012; 124 p.

5. BRASIL. Secretaria Especial de Programas, Pesquisas e Gestão Estratégica. Departamento de Pesquisas Judiciárias. Conselho Nacional de Justiça. Justiça em números 2019. Brasília: Editora do Conselho Nacional de Justiça, 2019; 236p.

6. CAMPOS MAMR, SCHOR N. Violência sexual como questão de saúde pública: importância da busca ao agressor. Saúde e Sociedade, 2008; 17(3): 190-200.

7. CAPEZ F. Da sanção penal. In: CAPEZ F. Curso de direito penal, volume 1, parte geral: arts. 1ํ a 120. 23. ed. São Paulo: Saraiva Educação, 2019; p. 646-648.

8. CRUZ MM. Sistema processual acusatório e inquérito policial no Brasil: uma análise comparativa entre o atual código de processo penal e o projeto de reforma. Trabalho de Conclusão do Curso (Graduação em Direito) Departamento de Ciências Jurídicas e Sociais. Universidade Regional do Noroeste do Estado do Rio Grande do Sul, ljuí, 2019; $51 \mathrm{p}$.

9. DELZIOVO CR et al. Qualidade dos registros de violência sexual contra a mulher no Sistema de Informação de Agravos de Notificação (Sinan) em Santa Catarina, 2008-2013. Epidemiologia e Serviços de Saúde, Santa Catarina, 2018; 27(1): 1-12.

10. DESLANDES SF, CAMPOS DS. A ótica dos conselheiros tutelares sobre a ação da rede para a garantia da proteção integral a crianças e adolescentes em situação de violência sexual. Ciência \& Saúde Coletiva, 2015; 20(7): 21732182.

11. EVANS DP, et al. As mulheres têm mais medo da lei que dos agressores: um estudo sobre a confiança pública na saúde e a reposta jurídica à violência contra mulheres em Santo André, São Paulo, Brasil. Cad. Saúde Pública. 2020; 36: 10.

12. FONTAN RD, SILVA VO. Principais consequências sofridas por vítimas de violência sexual no ambiente intrafamiliar. 2019. 21 f. TCC (Graduação) - Curso de Enfermagem, Centro Universitário Cesmac, Maceió, 2019.

13. GASPAR RS, PEREIRA MUL. Evolução da notificação de violência sexual no Brasil de 2009 a 2013. Caderno de Saúde Pública, 2018; 34(11): 1-10.

14. GOMES R. Da denúncia à impunidade: um estudo sobre a morbi-mortalidade de crianças vítimas de violência. Cadernos de Saúde Pública, 1998; 14(2): 301-311.

15. KISS L, et al. Brazilian policy responses to violence against women: government strategy and the help-seeking behaviors of women who experience violence. Health And Human Rights, 2012; 14(1): 64-77.

16. OLIVEIRA GLOJ, et al. Perfil epidemiológico de mulheres vítimas de violência sexual. Revista Saúde - UNG-SER, 2016; 10(1): 17.

17. PIAUÍ. Dispõe sobre a Organização Judiciária do Estado do Piauí e dá outras providências. Lei de Organização Judiciária do Estado do Piauí. Piauí, 2015.

18. PINTO LSS, et al. Políticas públicas de proteção à mulher: avaliação do atendimento em saúde de vítimas de violência sexual. Ciência \& Saúde Coletiva, 2017; 22(5): 1501-1508.

19. PLATT VB et al. Violência sexual contra crianças: autores, vítimas e consequências. Ciência \& Saúde Coletiva, 2018; 23(4): 1019-1031.

20. REYMÃO AEN, et al. A eficiência nos Tribunais Judiciários brasileiros: um olhar sobre o tribunal de justiça do estado do Pará. Revista Eletrônica Cnj, 2019; 1(3): 8-17.

21. SANTOS VA. As medidas protetivas e a garantia de direitos na perspectiva de famílias em situação de violência sexual intrafamiliar. 2010. 262 f. Tese (Doutorado) - Curso de Psicologia, Universidade de Brasília, Brasília, 2010.

22. SILVA LMP, et al. O Poder Judiciário como última instância de proteção às crianças e aos adolescentes: ações intersetoriais, investimento em recursos humanos e estruturação dos serviços. Revisto Latino-Americana de Enfermagem, 2012; 3(20): 444-452.

23. SOUSA EA. A atuação da rede de enfrentamento da violência contra a mulher no contexto da cidadania, sob o foco das políticas públicas no município de Picos-PI. 2018. 201 f. Tese (Doutorado) - Curso de Serviço Social, Universidade Federal de Pernambuco, Recife, 2018.

24. TRIGUEIRO TH et al. Vítimas de violência sexual atendidas em um serviço de referência. Cogitare Enfermagem, 2015; 2(20): 249-256.

25. VARGAS JD. Familiares ou desconhecidos? A relação entre os protagonistas do estupro no fluxo do Sistema de Justiça Criminal. Revista Brasileira de Ciências Sociais, 1999; 14(40): 63-82. 